\title{
Research Method of Silting the Mountain Reservoirs Under the Current Climate Change
}

\author{
Giorgi Metreveli ${ }^{1}$, Lia Matchavariani ${ }^{2,}{ }^{*}$ \\ ${ }^{1}$ Institute of Applied Ecology, FENS, Ivane Javakhishvili Tbilisi State University, Tbilisi, Georgia \\ ${ }^{2}$ Department of Geography, Faculty of Exact \& Natural Sciences, Ivane Javakhishvili Tbilisi State University, Tbilisi, Georgia \\ Email address: \\ giorgi.metreveli@tsu.ge (G. Metreveli), lia.matchavariani@tsu.ge (L. Matchavariani) \\ *Corresponding author
}

\section{To cite this article:}

Giorgi Metreveli, Lia Matchavariani. Research Method of Silting the Mountain Reservoirs Under the Current Climate Change. Journal of Water Resources and Ocean Science. Vol. 5, No. 2, 2016, pp. 22-27. doi: 10.11648/j.wros.20160502.11

Received: March 11, 2016; Accepted: March 21, 2016; Published: April 1, 2016

\begin{abstract}
The mountain reservoirs are an accumulator of the processing products of river banks and sediments. These elements form the silting prism and its bench, which are located in the reservoir and the riverbeds of the tributaries. As a result, there is increased riverbeds and there are a number of catastrophic flooding risk and deficit of the beach-forming sediment on the sea coast. The aim of our research is the estimation of accumulation of solid material in the reservoirs and tributaries, as well as a change of channel processes. In order to study the sedimentation prism-formation and equilibrium bad processes, the method of field experiment is proposed, which was used in the mountain reservoirs of Georgia. For analysis of obtained results were used the methods of mathematical statistics - least square method and differential calculus. The experiment showed that the final result of the reservoirs' silting is an accumulative terrace, which produced an equilibrium alluvial bed. Fractional distribution of sediments in silting prism is determined by reservoir control type and intra-annual distribution of fluvial sediments. The network of sediment extraction quarries has to be located along the reservoir taking into account this principle.
\end{abstract}

Keywords: Accumulate Terrace, Caucasus, Mountain Reservoir, Silting

\section{Introduction}

The current climate change has strengthened processes of sea shore abrasions and mountain reservoir sedimentation. High values of mountain reservoirs condition the current boom of construction of these facilities worldwide. A selection of their location occurs according to their characteristics, and due to this fact is ignored the threat that these reservoirs create to headrace population and infrastructure as a result of possible catastrophic floods, while in seaside countries it causes heavy deficit along the beachmaker sediments. Mentioned negative aspects are the result of the lack of corresponding knowledge. During designing project developers don't take into account rising of water level in beds of tributaries located above the reservoir.

Studies of reservoir silting worldwide, including Georgia are carried out starting from the 30's of the last century. The basic goal of these studies was the determination of operating time for the reservoirs, creation of calculation methodology of accumulated sediment volume and description of processes taking place in tailrace [1]. In 80's was executed global generalization of reservoirs, their integrated use and regional distribution [2]. In the same period reservoirs of the South Caucasus were studied [3]. A stochastic and probabilistic assessment of the flows and sediments from the viewpoint of their forecasting was also made in Georgia [4]. Fundamental studies on issues of reservoirs silting producing energy were carried out in Georgia [5], where the goal was an elaboration of the method of sediments' washout from reservoirs. Interesting studies were also conducted regarding reservoir ecology [6].

Nowadays, in many countries worldwide are especially intensified the studies from the viewpoint of silting, management and modeling of reservoirs; furthermore, monitoring, evaluation, sustainability, balancing, comparative analysis, as well as avoiding the effect on the Environment, catastrophic floods, provision of population security $[7,8,9$, $10,11,12,13,14,15,16,17,18,19,20,21,22]$, etc. 
Today the main attention is focused on accumulative processes taking place in headrace of water reservoirs, since this issue was not examined before. Especial interest in accumulative processes running in headrace is caused by the fact that without study of these processes is impossible to identify settlements and communication lines caught in the zone of catastrophic water floods and assess appropriate risks. The second important reason is that mentioned negatives appear in the middle phase of operation, while dramatic and sometimes tragic nature they take only after expiration of reservoirs' lifetime.

Sediments accumulated in water reservoirs, i.e. silting prism (SP) consists of two growing parts. First of them is a part formed right in the reservoir, and the second part is an accumulated body, so-called bench. Growth of the latter causes rising of water level in the river bed that lasts until SP reaches its maximum limit, i.e. the volume after which accumulative processes in the headrace completely cease. In these conditions river has already a developed equilibrium bed (EB) on the surface of SP, the parameters of which (length L and slope I) are so big that river is able to completely move sediments to the tailrace.

Because of the fact that the study of SP and EB formation processes and their parameters for acting water reservoirs is complicated, expensive and longstanding process, expected negatives are completely ignored during the selection of location for reservoirs. This problem is not highlighted in sufficient volumes, neither in Georgian, nor in foreign scientific-technical literature. Respectively, interests and safety of population domiciled below the reservoirs aren't taken into account when selecting their location, and doesn't occur determination of volumes and fractional composition of accumulated sediments and assessment of risks of seacoast abrasion caused by lack of sediments. Due to the same reason are not elaborated the methods of avoiding or adaptation of these negatives.

Natural experiments are the highly effective means for assessment of solid material accumulation and variations of bed processes in water reservoirs and tributaries and for filling the lack of knowledge. For these purposes must be created artificial reservoirs, where will be possible to carry out an integrated study of SP and EB formation processes for less than two years, to determine functional relations between their parameters and hydrological-hydraulic characteristics of the river. Obtained results allow us to elaborate recommendations on avoidance and adaptation of mentioned negatives.

\section{Study Area and Methods of Research}

For a study of SP and EB formation in time and space were selected three mountain rivers from the Southern slope of the Caucasus mountains with a different regime (mountain regions of Western and Eastern Georgia). Their relatively straight segments were obstructed by 1 -meter height dam and were covered by the network of longitudinal and cross sections of stationary observation points. This network contains water body and river bed above it, the length of which was at least two-times bigger than water body length. Planning of SP and its bench was made taking into account the frequency of floods and freshet of tributaries. Field studies were carried out using a differential GPS-receiver Leica GS08 (fig. 1), which is connected to a network of the National Agency of Public Registry and provides a high precision $( \pm 5$ $\mathrm{cm}$ ) of geodetic measurements throughout the country. For analysis of obtained results were used the methods of mathematical statistics (least square method) and differential calculus (bounds method). Approbation of calculation results were implemented at Gumati reservoir, which is constructed at the Rioni River in 1953 (West Georgia), and Sioni reservoir, created at the Iori River in 1963 (East Georgia).
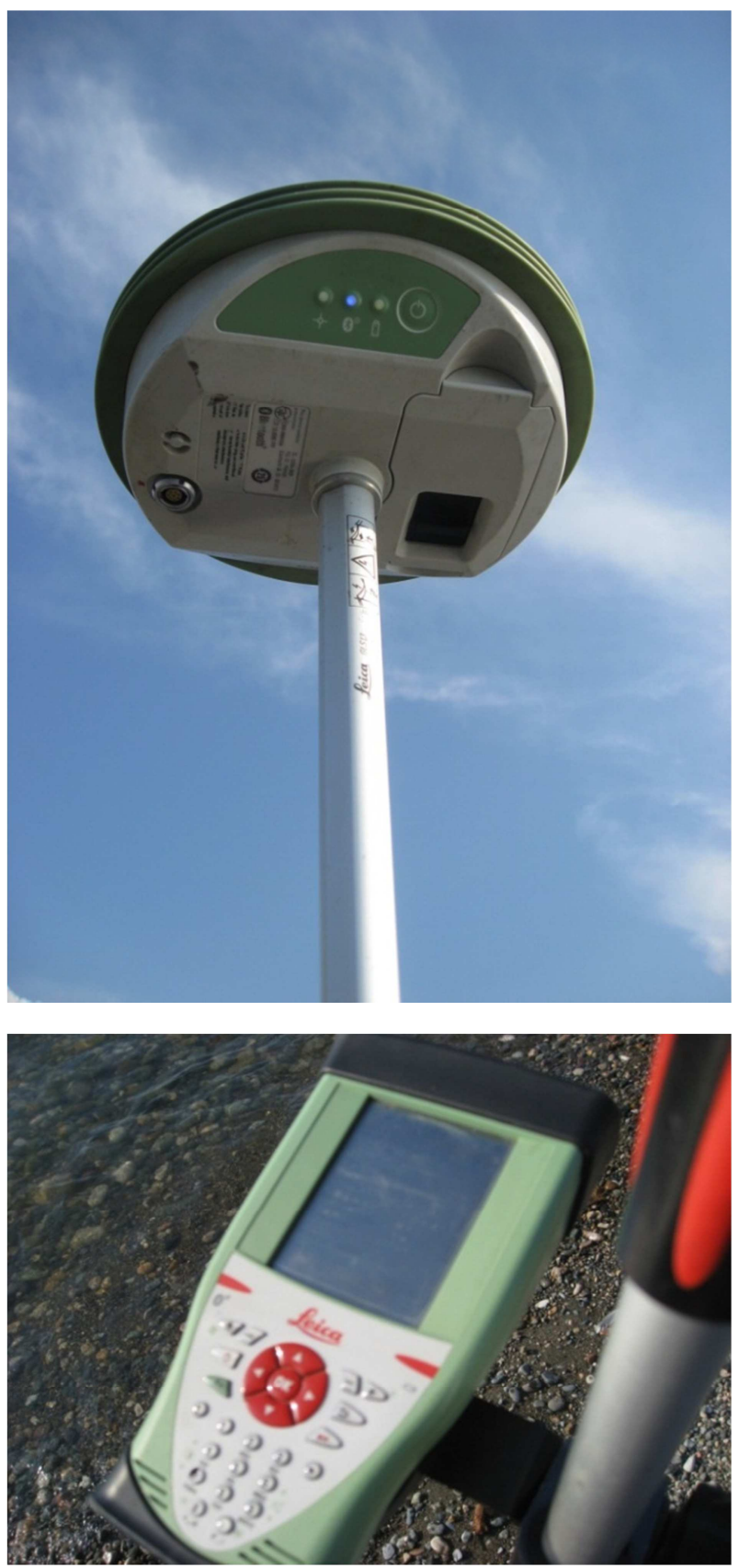

Figure 1. Differential GPS-receiver Leica GSO. 


\section{Results and Discussion}

As natural experiments (fig. 2) show, reservoir's silting is the most intensive in the first phase of operation. At this time the most part $(r \geq 70 \%)$ of tributary sediments and solid materials formed due to riverbank deformation experiences sedimentation. SP formation occurs simultaneously, but with different rate in water reservoirs and tributaries (fig. 3). Sediment fractions (clay - fine sand), the hydraulic size of which in turbulent medium $\mathrm{U} \leq 1.0 \mathrm{~m} / \mathrm{sec}$, is transported by streams in the initial phase of operation through the whole water reservoir and one part of them forms the layer with size corresponding to reservoir control type. The remaining part of such fractions $(\geq 30 \%)$ doesn't take part in prism formation, since it is transported by letting out water to the tailrace. Transportation of detritus (coarse sediments) in this phase to the tailrace occurs sporadically, during emergency water outlets.

In following phases the share and diameter of sediments transported from the reservoir gradually increase and reaches its maximum in the third phase of the operation. At the end of this phase SP reaches limit values of development and is formed as accumulation terrace, on which EB is developed by tributaries.

Development of SP and its bench becomes especially active, when coarse-fraction sediment $(d \geq 10,0 \mathrm{~mm})$, which is precipitated in the zone of flood curve forms crests. This accumulative formation has the form of beach ridge (fulls), which slope exposed towards dam is sharper than the bench slope formed in tributaries (fig. 3d). Such crest gradually increases in height, comes close to the dam and when reaches it, $\mathrm{SP}$ volume and EB length will become equal to their limit values.

The experiment showed that the rate of SP growth is diminishing - average annual volume $\left(\mathrm{r}_{\mathrm{s}}\right)$ of materials precipitated in water reservoir and tributaries is the biggest in the initial phase of operation, afterwards it decreases in time in second and third phase and finally becomes equal to zero, when SP reaches its limit value.

$$
\lim _{n \rightarrow T} r_{s}=0
$$

Time distribution $\left(\mathrm{r}_{\mathrm{u}}\right)$ of sediment transported from water reservoir is opposite to this process, it gradually increases and at the end of reservoir operation, i.e. after $\mathrm{T}$ time (in years) will become equal to the average annual volume $(\mathrm{R})$ of sediments $\left(\mathrm{r}_{\mathrm{u}}=\mathrm{R}\right)$ and this sediment along with letting out water completely moves to tailrace:

$$
\lim _{n \rightarrow T} r_{u}=0
$$

Here, $r_{s}$ and $r_{u}$ are average annual volumes $\left(\mathrm{m}^{3} /\right.$ year) of sediments precipitated in reservoirs and tributaries and sediments transported by the stream to tailrace, correspondingly, $\mathrm{R}$ is annual volume $\left(\mathrm{m}^{3} /\right.$ year) of sediments brought by tributaries to the water reservoir, $\mathrm{T}$ - duration of water reservoir operation time (years), while $\mathrm{n}=1,2, \ldots, \mathrm{T}-1, \mathrm{~T}$.

EB starts above the initial river bed, at height (h, m) of dam outlet (fig. 3c). It follows SP surface and ends at the imaginary cross section, above which the river permanently keeps its natural ability of sediment transportation. EB length (L) and slope (I\%o) determine the value of the SP surface area (F) and by means of this parameter is possible to calculate $F$ value in any phase of EB development. Processes of SP and EB formation proceeded with the rate corresponding to the ratio $(\mathrm{W} / \mathrm{V})$ of their useful capacity $(\mathrm{W})$ and annual amount of sediments $(\mathrm{V})$.

SP surface in limit state is represented by the plain inclined towards the dam (fig. 3d), which begins from dam outlet. Its area significantly (sometimes $\mathrm{f} \geq 60 \%$ ) exceeds reservoir surface (fig. 3a). It is extended in tributaries up to the cross section, to which reservoir's water flood curve reaches during floods and freshets. SP bench sizes basically are depended on hydrological and hydraulic characteristics of tributaries: bench length (L), dam outlet height (h), sediment diameter (d), maximum discharge of water and sediment $\left(\mathrm{Q}_{\mathrm{m}}, \mathrm{R}_{\mathrm{m}}\right)$ and inclination of the bed located above the water reservoir (I\%o):

$$
\mathrm{L}=\mathrm{f}\left(\mathrm{h}, \mathrm{Q}_{\mathrm{m}}, \mathrm{R}_{\mathrm{m}}, \mathrm{d}, \mathrm{I}^{-1}\right)
$$

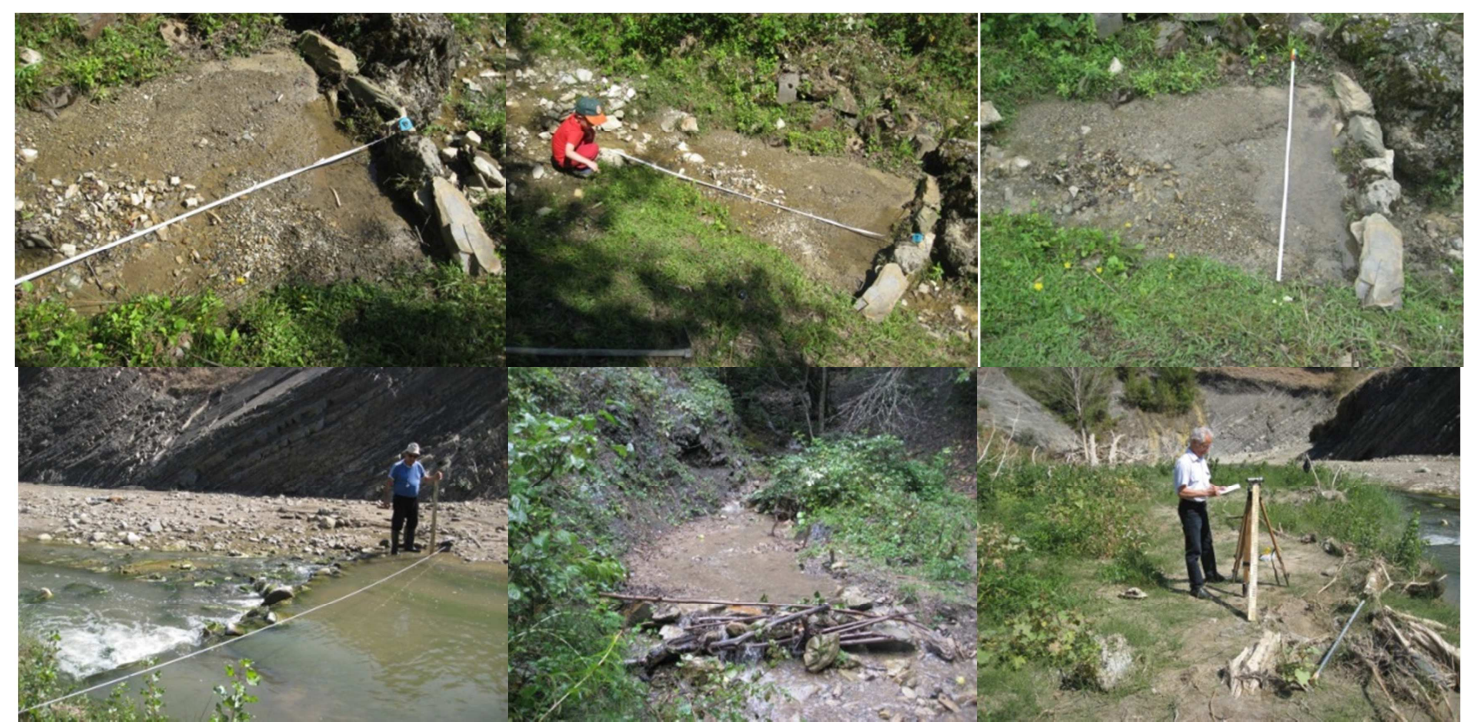

Figure 2. Natural experiment at mountain debris flows. 


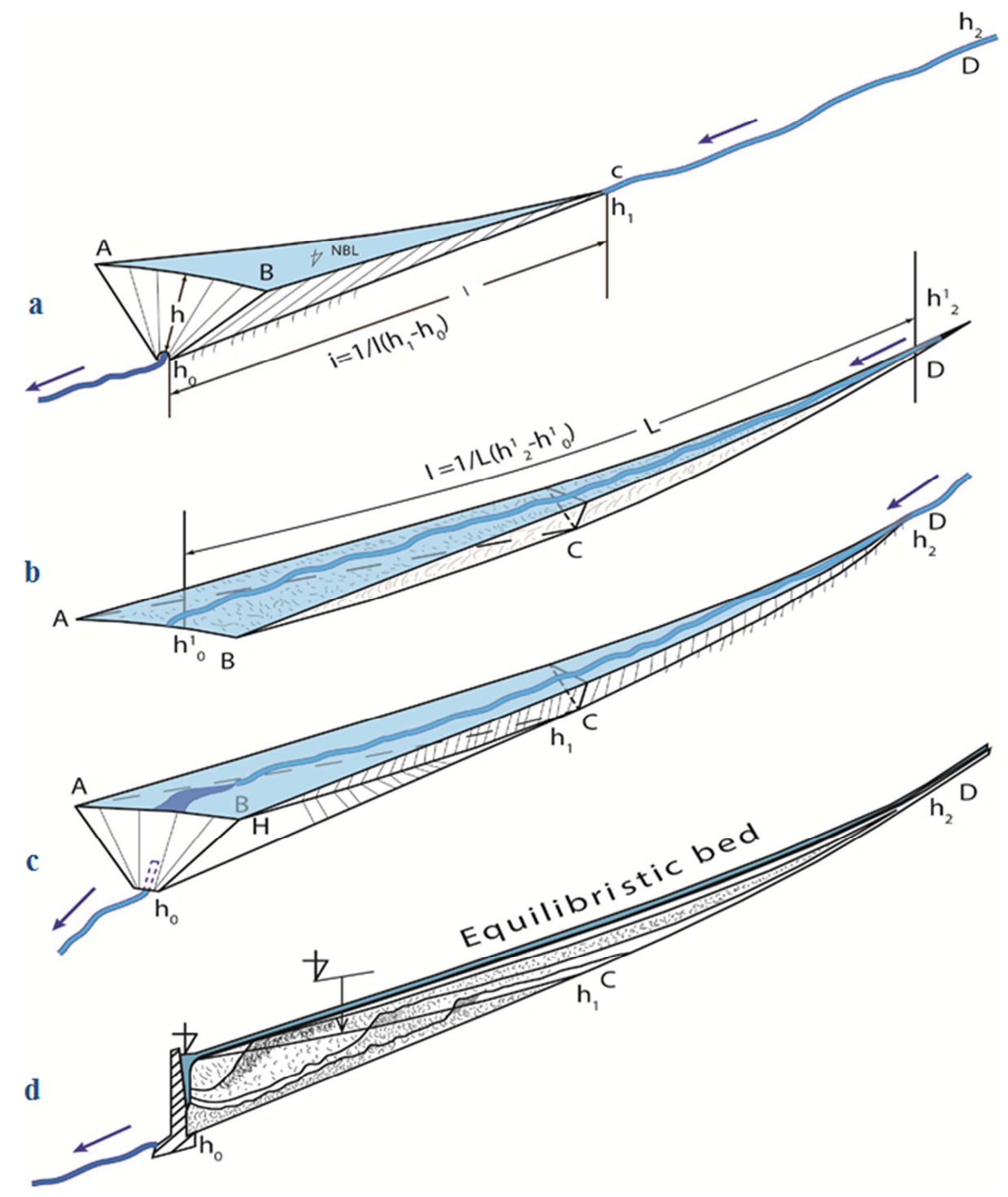

Figure 3. Transformation of silting prism and equilibrium bed.

At the same time EB length is inversely proportional to the inclination of that river section (I\%), which is located above the reservoir. This fact means that the more river bed is inclined, the shorter is EB. According to experimental results, a length of the latter (L) doesn't exceed a double length of the reservoir $(2 \mathrm{~S})$.

$$
\mathrm{L} \leq 2 \mathrm{~S}
$$

The experiment showed that the water flood risks for the population and infrastructure located above water reservoir increase proportionally to the height of SP and its bench. The more place is occupied by a bench in the river bed, the more high is a probability of flowage of the river.

A straight line is the simplest approximated form of EB. When the river crosses tectonic fault line its form comes closer to convex or concave curve. In this case it may be described by coordinates of the parabola, which begins from dam outlet and lasts up to above mentioned imaginary cross section.

Results of natural experiments are tested on Gumati and
Sioni water reservoirs, since SP and ES are nearest to limited values. Sediments accumulated during many decades in Gumati reservoir and in river bed located above have raised the Rioni river bed level so much that it every year overflows its banks and submerges adjacent settlements and infrastructure. Territory adjacent to Sioni reservoir is in a more dangerous situation, since sediments precipitated above the water reservoir already have raised river bed by 3-5 meters. Due to this fact Iori River several times overflows protective structures and heavily damaged riverine area, while it would seem that settlements are reliably protected by the dam.

$98 \%$ of Gumati reservoir are occupied by sediments, while Sioni reservoir already lost approx. $75 \%$ of volume. Both reservoirs are located in the active tectonic zone of the Southern slope of the Greater Caucasus. As of 2015 SP bench has changed river bed parameters in these reservoirs (approx. by 5-6 meters at Gumati and 2-3 meters at Sioni reservoir) so much that during floods and freshets these rivers every year overflow their banks and do damage to the settlements, infrastructure and environment. 
Prediction, based on calculations, made according to results of natural experiments in the near future (2025-2030 years) SP and river bed parameters will change by another $15-20 \%$ that creates a real risk of disaster for neighboring settlements. As a consequence the probability of catastrophic floods and related risks are so high that floods, which usually are repeated once in two decades $(\mathrm{P} \geq 5-10 \%)$, become a serious threat for population and environment.

\section{Conclusions}

- Natural experiment is a highly effective means for monitoring the formation process of water reservoir SR and EB and study of their functional relations with tributaries' parameters, especially under conditions of time shortage. Thanks to these experiments is possible to gather in short span of time cognitive and application information on designed water reservoirs that will allow population to avoid the risks of catastrophic floods, will reduce a lack of knowledge on mountain reservoirs and thereby the science will get a new necessary and effective tool for designing.

- Creation of SP begins from time of putting a reservoir in the operation and ends with its formation as accumulation terrace. During this process coarse-fraction sediments precipitate in the movement zone of flood curve - near the river heads of tributaries and above them. One part of fine-grained sediments distributed by the flow across the whole water reservoir, forms accumulative layer, while the rest of sediments follow let out water to the tailrace;

- Annual volume of material participating in the formation of SP and its bench is diminishing (waning) in time. Respectively, the process of SP and EB creation is diminishing, i.e. it is the most intense in the initial phase of reservoir operation and is negligible when SP and EB reach limit values.

- SP with limit value of volume completely covers reservoir and a part of a gorge above it up to the imaginary cross-section, above which a river permanently keeps a natural ability of sediment transportation.

- SP surface represents an inclined surface, which begins from dam outlet and lasts up to above mentioned imaginary cross section;

- EB is a river bed developed at the surface of SP, the parameters of which correspond to the natural ability of sediment transportation. After the formation of EB erosion-accumulation processes in the headrace are virtually ceased and these processes are managed by other (anthropological, tectonic, sedimentation) factors.

- In general, fractional distribution of sediments in SP is determined by water reservoir control type and intra-annual distribution of fluvial sediments. Respectively, sediment diameter in SP increases from the movement area of reservoir flood curve (from the headwaters of tributaries) to the above mentioned imaginary cross-section and reduces starting from this area towards the dam. SP is characterized by sediment foliation and drastic variation of its diameter both in vertical and horizontal directions, due to which the network of sediment extraction quarries has to be located along the reservoir taking into account this principle.

\section{Acknowledgements}

This study is funded by Shota Rustaveli National Science Foundation within the grant "Modern Methods of the Joint Problem Realization for Shore Protection and Hydropower" (\#AR/220/9-120/14).

\section{References}

[1] Shamov G. I. (1959). River sediments. Gidrometeoizdat, 378 p. (in Russian)

[2] Avakian A. B., Saltankin V. P. \& Sharapov V. A. Reservoirs. Moscow, Misl, 1987, 325 p. (in Russian)

[3] Metreveli G. S. (1985). Reservoirs of South Caucasus. L., Gidrometeoizdat, 130, 296 p. (in Russian)

[4] Svanidze G. G. (1977). Mathematical modeling of hydrological series. L., Gidrometeoizdat, 296 p. (in Russian)

[5] Gvelesiani L. G., Shmaltsel N. P. (1973). Mode of mountainous rivers sediment and reservoirs siltation. Hydrology of lakes and reservoirs. Part 2. Reservoir, 5th session, IHHC UNESCO, Moscow, 38-48

[6] Iordanishvili I. K. \& Iordanishvili K. D. (2012). Issues of mountain reservoirs eco-evolution of Georgia. Institute of Water Industry, GTU, Tbilisi, 186 c. (in Russian)

[7] Metreveli G. S., Kereselidze D. N. \& Rehviashvili Sh.D. (2004). The dynamic of silting prism of mountain reservoirs. Dynamics and Thermic of rivers, reservoirs and sea coastal zone. Proceedings of the VI Conference,. IWP RAS, Moscow, 70-73 (in Russian)

[8] Amitrano D., Di Martino G., Iodice A., Riccio D., Ruello G., Papa M. N., Ciervo F. \& Koussoube Y. (2013, July). High resolution SAR for monitoring of reservoirs sedimentation and soil erosion in semi-arid regions. Geoscience and Remote Sensing Symposium (IGARSS), 2013 IEEE International, 911-914

[9] Andredaki M., Georgoulas A., Hrissanthou V., \& Kotsovinos N (2014). Assessment of reservoir sedimentation effect on coastal erosion in the case of Nestos River, Greece. International Journal of Sediment Research, 29(1), 34-48

[10] Bennett S. J., Dunbar J. A., Rhoton F. E., Allen P. M., Bigham J. M., Davidson G. R., \& Wren D. G. (2013). Assessing sedimentation issues within aging flood-control reservoirs. Reviews in Engineering Geology, 21, 25-44

[11] Caputo M., \& Carcione J. M. (2013). A memory model of sedimentation in water reservoirs. Journal of Hydrology, Elsevier, 476, 426-432

[12] Detering M., \& Schuettrumpf H. (2014). Reservoir Siltation and Ecological Life Span of Dams. Wasser Wirtschaft, Springer, $104(1-2), 30-33$ 
[13] Dewals B., Rulot F., Erpicum S., Archambeau P., \& Pirotton M. (2012). Long-term sediment management for sustainable hydropower. Comprehensive Renewable Energy. Vol. 6, $355-376$

[14] Garg V., \& Jothiprakash V. (2013). Evaluation of reservoir sedimentation using data driven techniques. Applied Soft Computing, Elsevier, 13(8), 3567-3581

[15] Gopinath G., Ashitha M. K., \& Jayakumar K. V. (2014). Sedimentation assessment in a multipurpose reservoir in Central Kerala, India. Environmental Earth Sciences, 72(11), 4441-4449

[16] Hajji O., Abidi S., Habaieb H. \& Mahjoub M. R. (2014). Regionalization and contribution to the study of reservoirs sedimentation: Lakes of Cape Bon and the Tunisia Central. 11th International Conference on Hydroscience \& Engineering "Hydro-Engineering for Environmental Challenges", Germany, Proceeding 2014 (pp. 575-582)

[17] Hosseinjanzadeh H., Hosseini K., Kaveh K., \& Mousavi S. F. (2015). New proposed method for prediction of reservoir sedimentation distribution. International Journal of Sediment Research, 30(3), 235-240
[18] Mansikkamäki H. (2013). Monthly sedimentation in some reservoirs of hydroelectric stations in Finland. Fennia International Journal of Geography, 143 (1)

[19] Mattheus C. R., \& Norton M. S. (2013). Comparison of pond-sedimentation data with a GIS-based USLE model of sediment yield for a small forested urban watershed. Anthropocene, Elsevier, 2, 89-101

[20] Ran L., Lu X. X., Xin Z., \& Yang X. (2013). Cumulative sediment trapping by reservoirs in large river basins: A case study of the Yellow River basin. Global and Planetary Change, $100,308-319$

[21] Wisser D., Frolking S., Hagen S., \& Bierkens M. F. (2013). Beyond peak reservoir storage? A global estimate of declining water storage capacity in large reservoirs. Water Resources Research, 49(9), 5732-5739

[22] Yasir S. A., Crosato A., Mohamed Y. A., Abdalla S. H., \& Wright N. G. (2014). Sediment balances in the Blue Nile River basin. International Journal of Sediment Research, 29(3), 316-328 